\title{
Migraine in pregnancy and lactation: a clinical review
}

\author{
E Anne MacGregor
}

\section{Overview}

Migraine affects mostly women during their reproductive years and is far more prevalent than many people realise. Within 1 year, over $15 \%$ of women and $6 \%$ of men have attacks of migraine with or without aura. ${ }^{1}$ Although migraine without aura accounts for the majority of migraine, particularly in women, the overall 1-year prevalence of migraine with aura is around 5\% for women and $2 \%$ for men. ${ }^{1}$ Migraine prevalence varies with age, rising through early adult life, peaking at age 30-40 years and then declining in the late $40 \mathrm{~s}$ and after 50 years in both males and females. ${ }^{1}$ Drug treatment is usually necessary for effective control of migraine hence many women who are pregnant or planning a pregnancy will want to know what effects pregnancy will have on migraine and vice versa, and what treatments they can take safely during pregnancy and lactation.

\section{Search strategy}

A MEDLINE search using the search terms 'migraine' and 'pregnancy' identified 389 publications. The Cochrane search strategy for identifying reports of randomised controlled trials was run on this database. ${ }^{2}$ The search strategy identified 109 publications, which were scrutinised for relevancy to this review.

In addition, references from the author's own files, a hand-search of the journals Cephalalgia and Headache, and peer-reviewed presentations at international congresses were also considered.

\section{Planning a pregnancy}

Drugs and other teratogens exert their greatest effects on the fetus in the first trimester, often before the woman knows she is pregnant. Drug use during pregnancy is common, each women taking an average of four to five different medications. ${ }^{3}$ Although some of these, such as iron and vitamin supplements, are specifically recommended in pregnancy, analgesics, anti-emetics and antacids are also widely used by women, with or without migraine.

Given that migraine is a condition of the reproductive years, health care professionals are well placed to help women consider management options for planned pregnancies. If women are taking preventative treatments that are not recommended in pregnancy, they should be advised to consider stopping them and/or switching to a safer alternative. For drugs used to treat the symptoms of migraine, the aim should be to try to limit triptans to the first 2 weeks of the menstrual cycle, when the woman is unlikely to be pregnant. To reduce the risk of neural tube defects, all women of childbearing age should ensure a dietary intake of $400 \mu \mathrm{g}$ folic acid daily, with supplements as required, increasing to $600 \mu \mathrm{g}$ during pregnancy.

Women with migraine receiving assisted conception would particularly benefit from support and advice on

J Fam Plann Reprod Health Care 2007; 33(2): 83-93

(Accepted 25 January 2007)

The City of London Migraine Clinic, London, UK and Barts Sexual Health, St Bartholomew's Hospital, London, UK E Anne MacGregor, MFFP, Director of Clinical Research

Correspondence to: Dr Anne MacGregor, The City of London Migraine Clinic, 22 Charterhouse Square, London EC1M 6DX, UK. E-mail: anne.macgregor@sinoragram.co.uk management as treatment with gonadotrophin-releasing hormone analogues is frequently associated with headache. ${ }^{4,5}$

Headache can be symptomatic of emotional stress. Frequent pre-pregnancy headache is a strong predictor of poor general and emotional health during pregnancy and should alert the health care professional to assess these women for depressive disorders. ${ }^{6}$

\section{Effect of pregnancy on migraine}

Retrospective and prospective studies suggest that around $60-70 \%$ of migraineurs experience improvement in migraine during pregnancy; in around $20 \%$ attacks completely disappear (Table 1 and Figure 1). If migraine has not improved by the end of the first trimester it is likely to continue throughout pregnancy and postpartum. ${ }^{7}$

\section{Migraine without aura}

Women with pre-existing migraine without aura generally report improvement or cessation of migraine during pregnancy. Respite is greater for women with a history of menstrual or menstrually related migraine without aura than for women with no evidence of a menstrual association. ${ }^{8-10}$

\section{Migraine with aura}

In contrast to migraine without aura, women who have preexisting migraine with aura are more likely to continue to have attacks during pregnancy. ${ }^{9}$ Women with pre-existing migraine without aura may develop aura for the first time during pregnancy. ${ }^{11,12}$ Also, if a woman has her first ever migraine when pregnant, it is likely to be with aura. ${ }^{13,14}$

\section{Effect of migraine on pregnancy}

In general, women can be reassured that migraine, either with or without aura, does not have any adverse effects on the outcome of pregnancy in otherwise healthy women (Table 2). ${ }^{11,15,16}$ However, studies have been retrospective, with consequent potential error due to confounding and recall bias, and numbers included in the studies have been small with few data from large epidemiological studies. Banhidy et al. examined the risk of congenital abnormalities in infants born to women who had migraines and other headaches during pregnancy. ${ }^{17}$ They evaluated 22843 newborns or fetuses with congenital abnormalities, 38151 control newborn infants without any abnormalities and 834 controls with Down syndrome. Migraine during

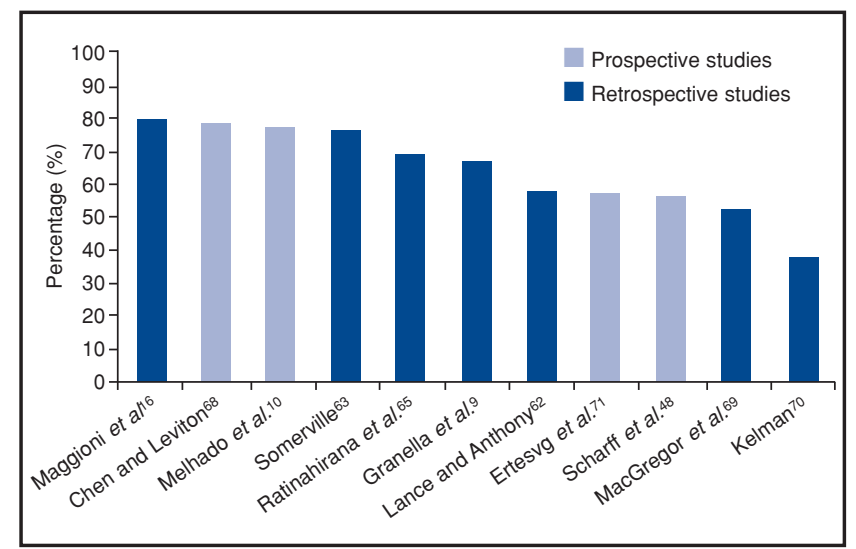

Figure 1 Percentage of women reporting improvement in pregnancy 


\section{MacGregor}

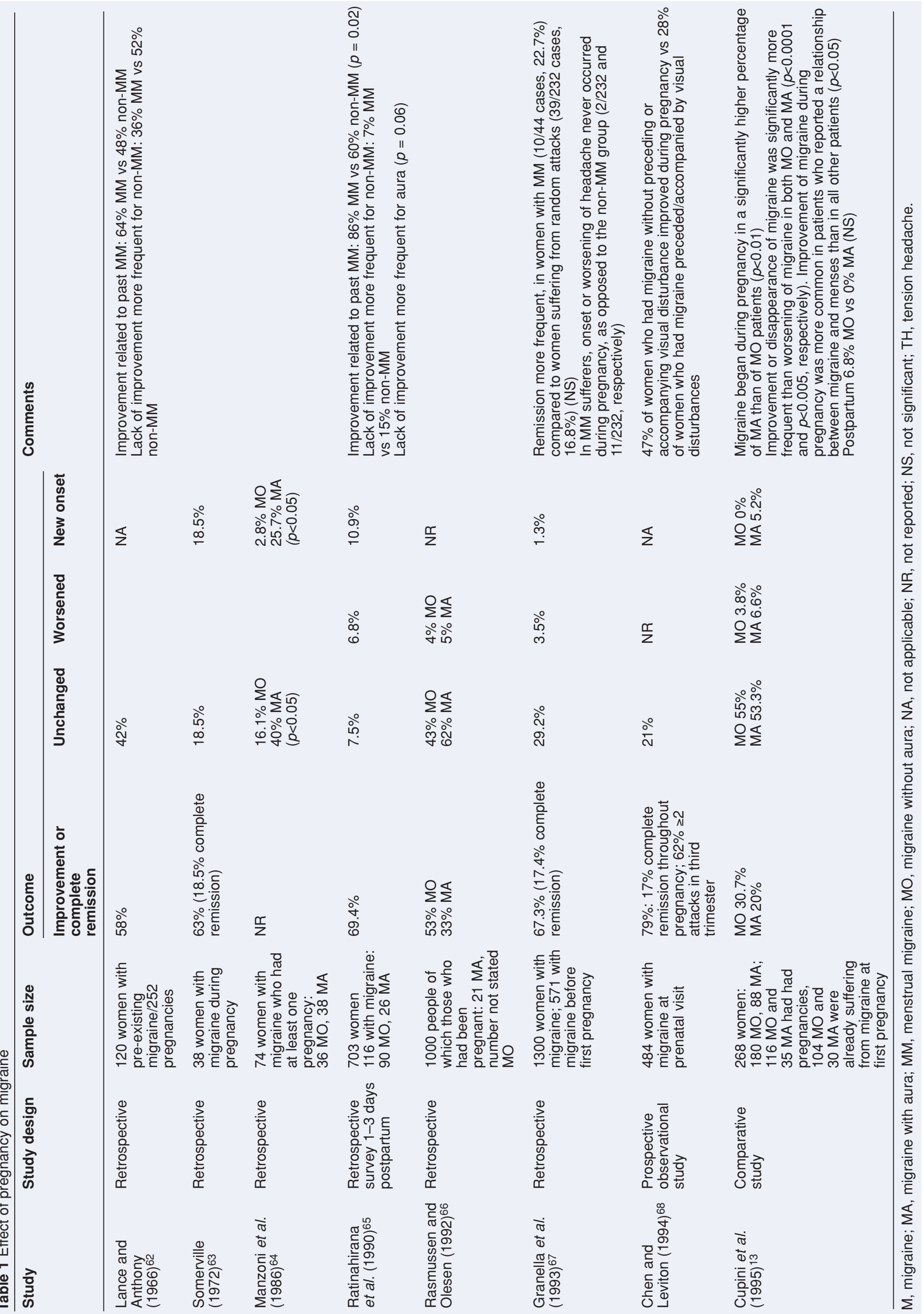




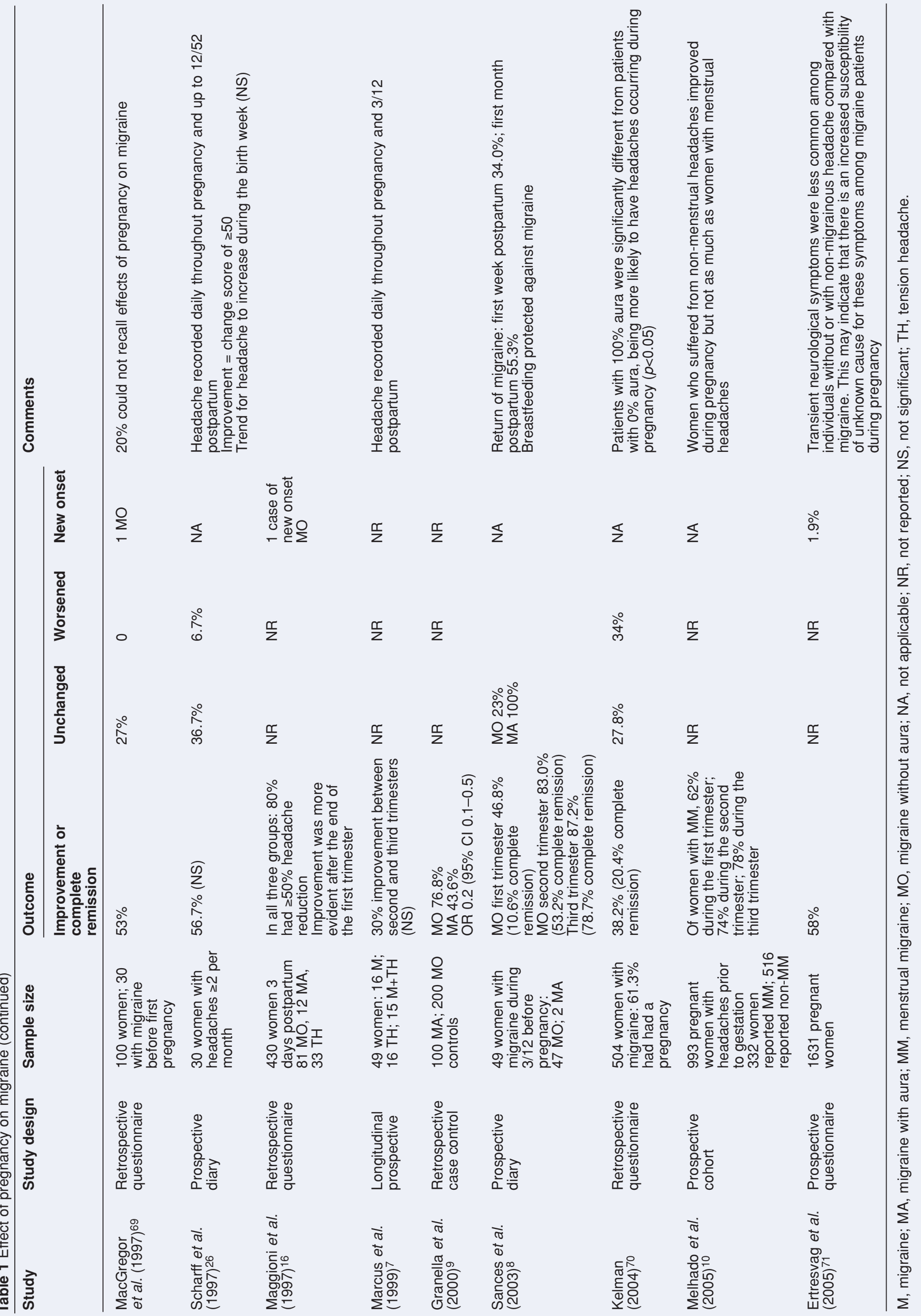


pregnancy affected $565(2.5 \%)$ mothers of the group with congenital abnormalities vs $713(1.9 \%)$ mothers in the normal group [crude prevalence odds ratio (POR) 1.3, 95\% CI 1.2-1.5] and 24 (2.9\%) pregnant women in the Down syndrome control group (crude POR 0.9, 95\% CI 0.6-1.3). Of all the parameters studied, the only positive finding was that limb deficiencies were associated with a higher rate of maternal migraines during the first trimester of pregnancy, for both the congenital abnormalities group vs matched normal group (adjusted POR 2.5, 95\% CI 1.1-5.8) and the congenital abnormalities group vs Down syndrome controls (adjusted POR 1.7, 95\% CI 1.3-3.0). Although this study has the benefit of large numbers, these data are not confirmatory and the effect of other independent variables, drug and non-drug treatments taken, and misdiagnosis of conditions mimicking migraine cannot be ruled out.

In women presenting with aura for the first time during pregnancy, the clinician should consider other disorders such as thrombocytopenia, cerebral venous sinus thrombosis or imminent eclampsia, which may present with symptoms not dissimilar from migraine. Headache with eclampsia can be associated with visual changes, including blurred vision, scotomata or bright flashing lights. To avoid incorrect diagnosis and ensure optimum treatment, a careful history and examination are mandatory.

There is an increasing body of evidence to support an association between migraine, pre-eclampsia and eclampsia. ${ }^{18-23}$ A recent case control study of 244 women with pre-eclampsia and 470 normotensive controls found that a history of migraine was associated with a 1.8 -fold increased risk of pre-eclampsia (95\% CI 1.1-2.7). Women who were 30 years or over when diagnosed with migraine had the highest risk (OR 2.8, 95\% CI 0.8-9.0). ${ }^{24}$ Overweight migrainous women, compared with lean nonmigrainous women, had a 12-fold increased pre-eclampsia risk (95\% CI 5.9-25.7).

\section{Postpartum}

Headache is common in the week following delivery, affecting around $30-40 \%$ of women. ${ }^{8,25,26}$ If there is any doubt about the diagnosis, rare causes such as cerebral venous thrombosis should be excluded. Cerebral venous thrombosis is estimated to occur in 1 per 2500 to 10000 deliveries and is most likely in women with hypercoagulability. It usually presents with neurological deficits, although severe progressive headache is reported in thrombosis of the superior sagittal sinus.

The risk of cerebral infarction, although not increased during pregnancy itself, is increased in the 6 weeks after delivery. ${ }^{27}$ Results from a recent study suggest that the risk is greater for women with a history of migraine (OR 16.9, 95\% CI 9.7-29.5) as well as women with pre-eclampsia and gestational hypertension (OR 4.4, 95\% CI 3.6-5.4).28 However, evidence is limited and prospective cohort studies are needed to confirm these findings.

Lactation generally leads to an improvement in the clinical course of migraine headache during the postpartum period. A longitudinal prospective study of headache during pregnancy and postpartum found that the headache index during the first three postpartum months was similar for patients who breastfed to that obtained during the second trimester of pregnancy. These data suggest that the improvement of migraine commonly seen during the second trimester of pregnancy continues into the postpartum time period if breastfeeding is maintained. ${ }^{7}$ A more recent study reported that migraine recurred within the first postpartum month in $100 \%$ of women who bottle-fed and in only $43.2 \%$ of those who breastfed $(p=0.0003) .8$

\section{Pathophysiology}

Fluctuations in estrogen levels, particularly declining levels after a stable estrogen state, are known to increase migraine in some susceptible women. ${ }^{29,30}$ Hence it might be expected that the high, stable levels of placental estrogen during the second and third trimesters of pregnancy would have a beneficial effect on migraine without aura. Immediately following delivery, estrogen levels rapidly fall, which could account for increased postpartum migraine. The protective effect of breastfeeding probably relates to stable low levels of estrogen since lactation inhibits ovulation. The mean time to ovulation after delivery is 189 days in breastfeeding women and 45 days in non-breastfeeding women. ${ }^{31}$ Resumption of ovulation and menstruation is associated with a return to pre-pregnancy patterns of migraine.

However, it is unlikely that the mechanism of migraine without aura relates solely to falling estrogen levels and there are many physical, biochemical and emotional changes in pregnancy that could account for improvement. It has been noted that pregnancy is associated with a state of analgesia, resulting from estrogen and progesterone working in combination to modulate opioid activity. ${ }^{32}$ Other relevant effects of the pregnant state include increased muscle relaxation and reduced hypoglycaemic response.

In susceptible women, high plasma concentrations of estrogen are associated with increased risk of migraine with aura. One mechanism that could account for this is the development of platelet hyperaggregation. ${ }^{33}$ Pregnancy is associated with varying degrees of platelet hyperaggregation, although opposing haemostatic changes attenuate this effect in most, but not all, women. ${ }^{34}$ Platelet hyperaggregation might also account for the increased risk of ischaemic stroke associated with migraine with aura and the development of pre-eclampsia in pregnancy. 35

\section{Investigations during pregnancy and lactation}

Radiological imaging is usually normal in migraine and is rarely helpful other than when indicated to exclude suspected secondary headache resulting from underlying pathology. Should investigations be required in pregnancy, such as for women presenting with atypical features of migraine or prolonged focal symptoms, they are the same as for non-pregnant women. Diagnostic investigations in pregnant patients should be as thorough as in non-pregnant patients and there is no reason to defer radiological testing purely on account of the pregnancy.

\section{Interventions}

Identification of non-hormonal triggers

Despite the strong association between hormones and migraine, identification and elimination of non-hormonal trigger factors still plays an important part in management. Assuming the concept of multiple factors acting in combination to trigger migraine, hormonal factors combine with non-hormonal triggers to increase the overall susceptibility to attacks. 36 Therefore, every effort should be made to identify and eliminate non-hormonal triggers. Women should be encouraged to avoid skipping meals, take regular exercise, drink plenty of fluids and try to maintain a regular sleep pattern.

\section{Drugs in pregnancy}

To avoid the potential for drug-related effects on pregnancy, it is important to minimise drug exposure in any woman who is planning pregnancy or who is at high risk of unplanned pregnancy. If possible, prophylactic medication should be discontinued and strategies for the management of acute attacks discussed. As few drugs as possible should be 


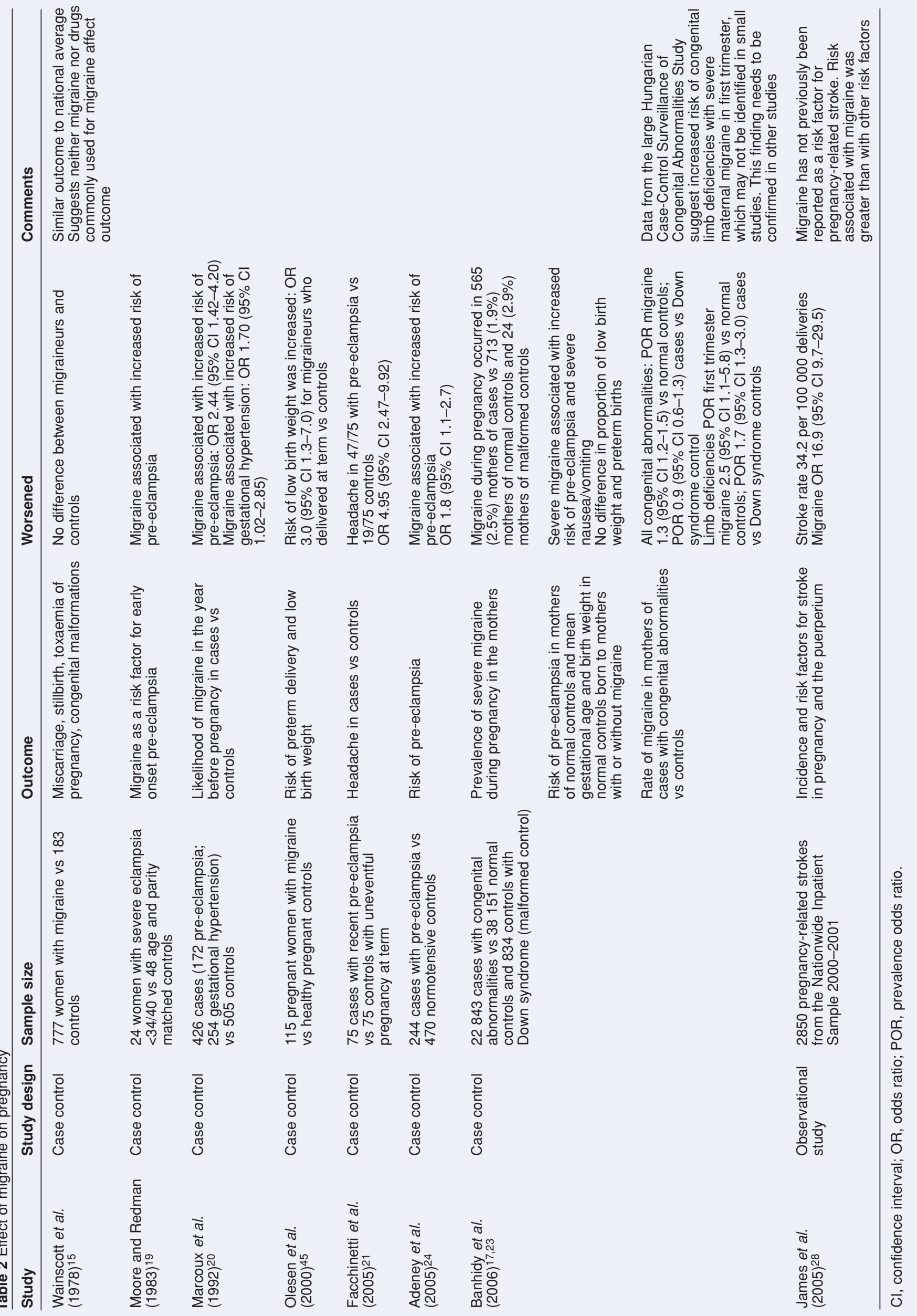


Table 3 Symptomatic drugs: use during pregnancy and lactation $37,57,72$

\begin{tabular}{|c|c|c|c|c|}
\hline Drug & $\begin{array}{l}\text { First } \\
\text { trimester }\end{array}$ & $\begin{array}{l}\text { Second } \\
\text { trimester }\end{array}$ & $\begin{array}{l}\text { Third } \\
\text { trimester }\end{array}$ & Lactation \\
\hline $\begin{array}{l}\text { Acetaminophen/ } \\
\text { paracetamol }\end{array}$ & $\checkmark$ & $\checkmark$ & $\checkmark$ & $\checkmark$ \\
\hline Codeine & $(\checkmark)$ & $(\checkmark)$ & $(\checkmark)$ & $\checkmark$ \\
\hline $\begin{array}{l}\text { Aspirin } \\
\text { Diclofenac } \\
\text { Ibuprofen } \\
\text { Naproxen }\end{array}$ & $\begin{array}{l}(\mathcal{V}) \\
(\mathcal{V}) \\
(\mathcal{V}) \\
(\mathcal{V})\end{array}$ & $\begin{array}{l}(\checkmark) \\
(\mathcal{V}) \\
(\checkmark) \\
(\mathcal{V})\end{array}$ & $\begin{array}{l}\text { Avoid } \\
\text { Avoid } \\
\text { Avoid } \\
\text { Avoid }\end{array}$ & $\begin{array}{l}\text { Avoid } \\
\checkmark \\
\checkmark \\
\checkmark\end{array}$ \\
\hline $\begin{array}{l}\text { Buclizine } \\
\text { Cyclizine } \\
\text { Domperidone } \\
\text { Doxylamine } \\
\text { Metoclopramide } \\
\text { Prochlorperazine* }\end{array}$ & $\begin{array}{l}(\mathcal{V}) \\
(\mathcal{J}) \\
(\mathcal{V}) \\
(\mathcal{V}) \\
(\mathcal{J}) \\
(\mathcal{V})\end{array}$ & $\begin{array}{l}(\mathcal{V}) \\
(\mathcal{V}) \\
(\mathcal{V}) \\
(\mathcal{V}) \\
(\mathcal{V}) \\
(\mathcal{V})\end{array}$ & $\begin{array}{l}(\mathcal{V}) \\
(\mathcal{V}) \\
(\mathcal{V}) \\
(\mathcal{V}) \\
(\mathcal{V}) \\
(\mathcal{V})\end{array}$ & $\begin{array}{l}2 \\
(2) \\
2 \\
2 \\
2 \\
(2)\end{array}$ \\
\hline $\begin{array}{l}\text { Dihydroergotamine } \\
\text { Ergotamine }\end{array}$ & $\begin{array}{l}\mathrm{Cl} \\
\mathrm{Cl}\end{array}$ & $\begin{array}{l}\mathrm{Cl} \\
\mathrm{Cl}\end{array}$ & $\begin{array}{l}\mathrm{Cl} \\
\mathrm{Cl}\end{array}$ & $\begin{array}{l}\mathrm{Cl} \\
\mathrm{Cl}\end{array}$ \\
\hline $\begin{array}{l}\text { Almotriptan } \\
\text { Eletriptan } \\
\text { Frovatriptan } \\
\text { Naratriptan } \\
\text { Rizatriptan } \\
\text { Sumatriptan } \\
\text { Zolmitriptan }\end{array}$ & $\begin{array}{l}\text { ID } \\
\text { ID } \\
\text { ID } \\
?(\mathcal{}) \\
?(\mathcal{}) \\
?(\mathcal{(}) \\
\text { ID }\end{array}$ & $\begin{array}{l}\text { ID } \\
\text { ID } \\
\text { ID } \\
?(\mathcal{}) \\
?(\mathcal{}) \\
?(\mathcal{}) \\
\text { ID }\end{array}$ & $\begin{array}{l}\text { ID } \\
\text { ID } \\
\text { ID } \\
?(\sqrt{ }) \\
?(\mathcal{}) \\
?(\mathcal{}) \\
\text { ID }\end{array}$ & $\begin{array}{l}\text { ID } \\
(\mathcal{V}) \\
\mathrm{ID} \\
(\mathcal{V}) \\
(\mathcal{V}) \\
\mathcal{J} \\
(\mathcal{V})\end{array}$ \\
\hline $\begin{array}{l}\text { Chlorpromazine } \\
\text { IM }^{*}\end{array}$ & $(\sqrt{ })$ & $(\checkmark)$ & $(\checkmark)$ & $\checkmark$ \\
\hline $\begin{array}{l}\text { Magnesium } \\
\text { sulphate IV* }\end{array}$ & $(\checkmark)$ & $(\checkmark)$ & $(\checkmark)$ & $(\checkmark)$ \\
\hline Prednisolone* & $(\checkmark)$ & $(\sqrt{ })$ & $(\checkmark)$ & $(\sqrt{ })$ \\
\hline
\end{tabular}

$\mathrm{CI}$, contraindicated; ID, insufficient data; IM, intramuscular; IV, intravenous; ? $(\mathcal{})$, limited data but probably safe; $(\mathcal{})$, data suggest unlikely to cause harm; $\checkmark$, no evidence of harm; *, for emergency treatment of migraine not responding to standard measures.

used, which have the least potential to cause damage, in the lowest effective dose. Although many of the drugs taken by unsuspecting pregnant women rarely cause harm, there is a difference between reassuring the pregnant woman that what she has taken is unlikely to have affected the pregnancy and advising her what she should take for future attacks. Most evidence of safety is circumstantial; few drugs have been tested during pregnancy and lactation because of the obvious ethical limitations of undertaking clinical trials. This lack of data means that use of most drugs in pregnancy is unlicensed. Drugs should only be considered if the potential benefits to the woman and fetus outweigh the potential risks. The woman should be given sufficient information about any known risks, and make her own decision about its use, with clear documentation of the discussion.

In the UK, further advice is available from local drug information centres and from the National Teratology Information Service (see Further Information).

\section{Symptomatic treatment}

The treatment of migraine during pregnancy is the same as for the non-pregnant state, with some exceptions (Table 3).

\section{Analgesics}

Acetaminophen/paracetamol: Despite lack of formal clinical trial evidence, paracetamol has been used for over 40 years and there is substantial information on the safety of therapeutic doses in pregnancy. It is the analgesic of choice for the short-term relief of mild to moderate pain and pyrexia during pregnancy. 37

Aspirin: Clinical and epidemiological data from large numbers of women who have taken analgesic doses of aspirin during pregnancy provide evidence of its safety in the first and second trimesters. ${ }^{38}$ It should be used with caution near term as its effect on platelet function increases the risk of prolonged labour, postpartum haemorrhage and neonatal bleeding. In common with non-steroidal antiinflammatory drugs (NSAIDs), aspirin may be associated with premature closure of the fetal ductus arteriosus.

Codeine: Codeine is not generally recommended for the management of migraine in the UK. ${ }^{39}$ However, occasional use in doses found in combined analgesics is unlikely to cause harm.

\section{NSAIDS}

There are insufficient data to support the use of NSAIDs other than ibuprofen, which can be given in doses not exceeding $600 \mathrm{mg}$ daily. ${ }^{40}$ The available data do not indicate that exposure to ibuprofen before 30 weeks of pregnancy is associated with an increased risk of malformations or spontaneous miscarriage. If an NSAID is required in the first or second trimester, ibuprofen would be the preferred agent. However, chronic exposure or exposure to high doses after 30 weeks is associated with an increased risk of premature closure of the ductus arteriosus and oligohydramnios. This is related to the inhibitory effect of ibuprofen on prostaglandin activity. In circumstances where the clinical condition requires treatment with NSAIDs during the third trimester, the fetus should be monitored regularly to detect any potential adverse effects. 37

\section{Anti-emetics}

Buclizine, chlorpromazine, cyclizine, domperidone, metoclopramide and prochlorperazine have been used widely in pregnancy without reports of adverse effects.

\section{Ergots}

Ergotamine and dihydroergotamine are contraindicated as uterine hypertonicity and vascular disruption increase the risk of miscarriage. ${ }^{41}$

\section{Triptans}

All seven triptans (almotriptan, eletriptan, frovatriptan, naratriptan, rizatriptan, sumatriptan and zolmitriptan) are available on prescription in the UK. Sumatriptan is also available without prescription from pharmacies.

Safety of triptans during pregnancy has yet to be confirmed, so although women using triptans can be reassured, continued use during pregnancy is not recommended unless no other treatment is effective.

Health care professionals are encouraged to report the outcome of pregnancy in any women exposed to the relevant safety databases (see Further Information). The registries are based on observational, case registration and follow-up studies designed to detect evidence of teratogenicity associated with specific medications. Risk of birth defects, as defined by the Centers for Disease Control and Prevention, is compared with published risks both in women in the general population and in women with the underlying condition being treated, if available. 42

Sumatriptan: Data from the large sumatriptan safety database are reassuring and confirm that inadvertent exposure to sumatriptan during pregnancy has not been associated with adverse outcomes. The risk of first trimester birth defects in the Sumatriptan Pregnancy Registry (1996 to 30 April 2006) is $16 / 371$ (i.e. $4.3 \%, 95 \%$ CI $2.6-7.1 \%$ ). This compares favourably with the 3-5\% risk of birth defects in the general population. However, although these data indicate that use of sumatriptan in early pregnancy does not result in a large increase in teratogenic risk, they do not rule out the possibility of a small increase in risk for a specific birth defect. 
Shuhaiber et al. compared pregnancy outcome after exposure to sumatriptan with that of disease-matched controls and non-teratogen controls. There were no differences in the rates of live births, spontaneous miscarriages, therapeutic terminations or major birth defects among the three groups. This prospective study suggests that the use of sumatriptan during organogenesis is not associated with an apparent increased risk of major birth defects. ${ }^{43}$

O'Quinn et al. compared perinatal pregnancy outcomes in women who did and did not use subcutaneous sumatriptan after conception. This open-label, prospective study was conducted in 168 pregnancies that included 76 first trimester exposures to sumatriptan. There were no differences in pregnancy outcome between the two groups. ${ }^{44}$

Olesen et al. reviewed data from the PharmacoEpidemiological Prescription Database of North Jutland County regarding all women who had given birth in the county of North Jutland from 1991 to 1996. They identified 34 women exposed to sumatriptan during pregnancy. Using logistic regression models, their pregnancy outcome was compared with two groups of pregnant women: healthy women $(n=15955)$ and migraine controls $(n=89)$, defined as migraine patients who did not redeem prescriptions for migraine treatment during pregnancy. They found that the risk of preterm delivery was elevated among women exposed to sumatriptan compared with migraine controls (OR 6.3, 95\% CI 1.2-32.0) and healthy women (OR 3.3, $95 \%$ CI 1.3-8.5). The risk of a low birth weight infant was increased (OR 3.0, 95\% CI 1.3-7.0) for all migraine patients who delivered at term $(n=115)$ compared with the outcome of healthy pregnancies. ${ }^{45}$ Although these findings could be due to drug exposure or disease severity, they have not been replicated in other studies.

A study of the Swedish Medical Birth Registry identified 658 women who had used sumatriptan and noted that the infants were more likely to be preterm and with a birth weight under $2500 \mathrm{~g}$. However, this was nonsignificant. No other differences between those exposed to sumatriptan and women using other drugs for migraine during pregnancy were noted. 46

Rizatriptan: Data from the rizatriptan Pregnancy Registry and reports from other sources do not suggest that treatment during pregnancy predisposes patients to spontaneous miscarriages or congenital anomalies above the normal rate. However, the number of reports is small. From June 1998 to 31 July 2006, 74 women have been enrolled in the Registry, 67 prospectively and seven retrospectively. Of the 67 prospective reports, 21 pregnancy outcomes are pending and 11 are unknown because the patients have been lost to follow-up. Of 30 live births, 28 were normal healthy term infants, one infant born at 35 weeks had hypospadias, and one infant died at 24 weeks, attributed to an incompetent cervix. One late fetal death at approximately 37 weeks was attributed to a cord accident. One pregnancy ended in an elective termination at 21 weeks' gestation following prenatal diagnosis of multiple anomalies due to partial replication of chromosome 3 attributed to advanced maternal age. Three spontaneous miscarriages under 12 weeks have been reported. Of the seven retrospective reports, three describe infants with congenital anomalies.

Other triptans: There are insufficient data on other triptans.

\section{Specific prophylaxis for migraine in pregnancy \\ Non-drug prophylaxis}

Non-drug therapies, such as relaxation, biofeedback and physical therapy, are safe and effective treatment alternatives for $80 \%$ of pregnant women. ${ }^{47}$ Further, the benefits are maintained beyond pregnancy. ${ }^{48}$

\section{Drug prophylaxis (Table 4)}

Low-dose aspirin

There has been one small trial involving 28 pregnant women with frequent or severe migraine attacks taking lowdose aspirin (75 mg) for migraine prophylaxis. There was no placebo control but 22 women reported subjective improvement. ${ }^{49}$ The authors base their rationale for using aspirin to prevent migraine on its ability to counteract the platelet activation that occurs in pregnancy. Low-dose aspirin has been extensively studied in pre-eclampsia during pregnancy with no increase in bleeding complications and negligible effects on the ductus arteriosus.

\section{Beta-blockers}

There is about a $25 \%$ risk of intrauterine growth retardation when atenolol is used at anti-hypertensive doses to treat essential hypertension in pregnancy. ${ }^{50}$ Other beta-blockers have not been systematically studied but it is generally assumed that this is a class effect, although a causative effect related to the underlying hypertension has not been ruled out. On this basis, if prophylaxis is considered necessary during pregnancy the lowest effective dose of propranolol or metoprolol are the drugs of choice. If betablockers are used in the third trimester, treatment should be stopped 2-3 days before delivery in order to reduce the likelihood of fetal bradycardia and a reduction in uterine contraction. Infants exposed to propranolol in utero should be monitored for hypoglycaemia. .51

\section{Antidepressants}

There are conflicting data regarding limb deformities associated with use of amitriptyline during pregnancy, although these have been associated with high doses used for the management of depression. There are no reports associated with low doses between 10 and $50 \mathrm{mg}$ at night used for pain management and migraine. Tachycardia, irritability, muscle spasms and convulsion have been reported in neonates of women taking antidepressive doses. Where clinically possible, it is recommended that the dose is tapered 3-4 weeks before delivery.

\section{Anti-epileptics}

Preliminary pregnancy registry information for topiramate shows no suggestion of fetal abnormalities or increased rate of miscarriage. Other anti-epileptic agents prescribed for migraine prophylaxis cannot justifiably be recommended during pregnancy. Sodium valproate, increasingly used for migraine prophylaxis, is contraindicated during pregnancy in the absence of epilepsy as there is a high risk of fetal abnormalities. 52 Indeed, women prescribed sodium valproate for migraine must use effective contraception. Gabapentin, although safe for use in pregnancy, is considered at best to be a third-line prophylactic agent. ${ }^{39}$

\section{Calcium channel blockers}

Verapamil has limited efficacy and although it is generally considered safe, it is not recommended for migraine prophylaxis in pregnancy. Further, it has a tocolytic effect on the uterus, so should be avoided in late pregnancy.

\section{Other drugs}

Data for pizotifen are limited but there are no reports of adverse outcomes during pregnancy. Methysergide is contraindicated.

Many pregnant women use dietary supplements during pregnancy incorrectly assuming that because they are not 
Table 4 Prophylactic drugs: use during pregnancy and lactation $37,57,72$

\begin{tabular}{|c|c|c|c|c|}
\hline Drug & $\begin{array}{l}\text { First } \\
\text { trimester }\end{array}$ & $\begin{array}{l}\text { Second } \\
\text { trimester }\end{array}$ & $\begin{array}{l}\text { Third } \\
\text { trimester }\end{array}$ & Lactation \\
\hline Amitriptyline & $(\mathcal{})$ & $(\checkmark)$ & $(\boldsymbol{})$ & $(\sqrt{ })$ \\
\hline Low-dose aspirin & $(\sqrt{\prime})$ & $(\checkmark)$ & Avoid & Avoid \\
\hline Atenolol & Avoid & Avoid & Avoid & $(\checkmark)$ \\
\hline Gabapentin & $?(\checkmark)$ & $?(\sqrt{ })$ & $?(\checkmark)$ & ID \\
\hline Methysergide & $\mathrm{Cl}$ & $\mathrm{Cl}$ & $\mathrm{Cl}$ & $\mathrm{Cl}$ \\
\hline Metoprolol & $(\mathcal{})$ & $(\checkmark)$ & $(\checkmark)$ & $\checkmark$ \\
\hline Pizotifen & ID & ID & ID & ID \\
\hline Propanolol & $(\sqrt{ })$ & $(\sqrt{ })$ & $(\sqrt{ })$ & $\checkmark$ \\
\hline Topiramate & ID & $(\checkmark)$ & $(\sqrt{)}$ & ID \\
\hline Valproate & $\mathrm{Cl}$ & ID & ID & $\checkmark$ \\
\hline Verapamil & $(\mathcal{V})$ & $(\sqrt{ })$ & Avoid & $\checkmark$ \\
\hline
\end{tabular}

$\mathrm{Cl}$, contraindicated; ID, insufficient data; ? $(\checkmark)$, limited data but probably safe; $(\checkmark)$, data suggest unlikely to cause harm; $\checkmark$, no evidence of harm.

'drugs' they must be safe. This belief is compounded by personnel in health food stores who are likely to give inadequate or even incorrect advice about the safety of these products. ${ }^{53,54}$ Having a reasonable knowledge of the efficacy and safety of some of the commonly used herbs and vitamins is useful when counselling pregnant women (Table 5).

Ginger is often used for morning sickness during the first trimester of pregnancy. In extensive reviews of studies using ginger as an agent to reduce morning sickness, several authors have concluded that ginger, in doses of around $1 \mathrm{~g}$ daily, may be beneficial. A recent review of six double-blind randomised controlled trials with a total of 675 participants and a prospective observational cohort study $(n=187)$ showed efficacy in the absence of significant side effects or adverse effects on pregnancy outcomes. Some authorities still have strong reservations based mainly on a lack of clear safety data rather than reports of actual fetal or maternal harm and consider that more observational studies, with larger sample sizes, are needed. ${ }^{55}$ If the woman has other medical conditions or is taking medication it is advisable for her to consult her general practitioner before using ginger to minimise the development of possible adverse effects. ${ }^{37}$

Vitamin B6 (pyridoxine) is included in most multivitamins recommended in pregnancy with doses ranging from 10 to $25 \mathrm{mg}$. Women who take a multivitamin containing vitamin B6 during the first 6 weeks of pregnancy experience significantly less nausea than women who do not take a multivitamin. ${ }^{56}$ As with most vitamins, megadoses of vitamin B6 are neither necessary nor recommended.

\section{Managing migraine during breastfeeding}

Although recent studies suggest that the number of women choosing to breastfeed is rising, there is also evidence that women do not initiate breastfeeding or discontinue because

Table 5 Herbs/vitamins for migraine: use during pregnancy and lactation 37,55

\begin{tabular}{|c|c|c|c|c|}
\hline Drug & $\begin{array}{l}\text { First } \\
\text { trimester }\end{array}$ & $\begin{array}{l}\text { Second } \\
\text { trimester }\end{array}$ & $\begin{array}{l}\text { Third } \\
\text { trimester }\end{array}$ & Lactation \\
\hline $\begin{array}{l}\text { Vitamin B2 } \\
\text { (riboflavin) }\end{array}$ & $\boldsymbol{J}^{*}$ & $\boldsymbol{J}^{*}$ & $\boldsymbol{V}^{*}$ & $\boldsymbol{S}^{*}$ \\
\hline $\begin{array}{l}\text { Vitamin B6 } \\
\text { (pyridoxine) }\end{array}$ & $\boldsymbol{S}^{*}$ & $\boldsymbol{J}^{*}$ & $\boldsymbol{J}^{*}$ & $\boldsymbol{J}^{*}$ \\
\hline $\begin{array}{l}\text { Coenzyme Q10 } \\
\text { Feverfew } \\
\text { Butterbur } \\
\text { Ginger }\end{array}$ & $\begin{array}{l}\text { ID } \\
\text { Cl } \\
\text { ID } \\
\left(\checkmark_{3}\right)^{*}\end{array}$ & $\begin{array}{l}\mathrm{ID} \\
\mathrm{Cl} \\
\mathrm{ID} \\
(\mathcal{V})^{*}\end{array}$ & $\begin{array}{l}\text { ID } \\
\mathrm{Cl} \\
\mathrm{ID} \\
(\checkmark)^{*}\end{array}$ & $\begin{array}{l}\mathfrak{J}^{*} \\
\mathrm{Cl} \\
\mathrm{ID} \\
(\checkmark)^{*}\end{array}$ \\
\hline
\end{tabular}

$\mathrm{Cl}$, contraindicated; ID, insufficient data; ? $(\checkmark)$, limited data but probably safe; $(\checkmark)$, data suggest unlikely to cause harm; $\checkmark$, no evidence of harm; $\boldsymbol{V}^{*}$, avoid megadoses. of their concerns about taking medication. ${ }^{57}$ Unfortunately, many women and health care professionals rely on information in the package inserts, which may not be accurate. Maintaining breastfeeding during drug treatment is increasingly recommended.

Headaches immediately postpartum can be severe, warranting effective treatment. Milk production on the first or second day postpartum is so low that the overall dose of any medication transferred is usually insignificant. In the following days drug exposure to the baby may be minimised if the mother takes medication immediately following breastfeeding or just before the baby is due a longer sleep period.

\section{Acute drug treatment (Table 3 ) \\ Analgesics}

Acetaminophen/paracetamol is the analgesic of choice during breastfeeding.

Aspirin: is excreted in breast milk so breastfeeding mothers should avoid its use because of the theoretical risk of Reye's syndrome and impaired platelet function in susceptible infants, although occasional use by the mother is unlikely to cause adverse effects.

Codeine: occasional use of over-the-counter drugs containing codeine is unlikely to cause harm, although large doses of codeine excreted in the breast milk can cause sedation and respiratory depression.

\section{NSAIDS}

The concentration of NSAIDs in breast milk is very low and is therefore unlikely to affect the infant.

\section{Anti-emetics}

There is no evidence to suggest that buclizine, chlorpromazine, cyclizine or prochlorperazine cannot be used during breastfeeding.

Domperidone, as well as being a prokinetic anti-emetic, is a dopamine agonist that stimulates prolactin. Since it does not cross the blood-brain barrier it is preferred to metoclopramide. Mean milk volume can increase by over $40 \%$ over 7 days. Milk levels of domperidone are minimal (only $1.2 \mathrm{ng} / \mathrm{ml}$ ).

Metoclopramide increases milk production by up to $100 \%$ at doses of 10-15 mg three times a day. The amount of metoclopramide transferred into breast milk is small, ranging from 28 to $157 \mu \mathrm{g} / \mathrm{l}$. The most significant adverse effects are extrapyramidal jerks and gastric cramping.

\section{Ergots}

Ergotamine and dihydroergotamine should not be used during breastfeeding as they inhibit lactation.

\section{Triptans}

The bioavailability of drugs and the amount of medication presented in milk throughout the day are two factors relevant to the safety of breastfeeding. Table 6 shows the oral bioavailabilty, $T_{1 / 2}$ and $T_{\max }$ for the seven triptans.

The most extensive triptan database is for sumatriptan. The excretion of a $6 \mathrm{mg}$ subcutaneous dose of sumatriptan in breast milk was studied in five subjects. 58 The concentration in milk corresponded to an infant exposure of only $3.5 \%$ of the mother's dose. The oral bioavailability is only $14 \%$ therefore the infant would only absorb $0.5 \%$ of the mother's dose. Since sumatriptan is usually administered as a single dose at infrequent intervals, the low level of excretion in breast milk suggests that continued breastfeeding following its use would not pose a significant risk to the infant. Despite the Summary of Product Characteristics (SPC), at least one authority sanctions use of 
Table 6 Triptan pharmacokinetics

\begin{tabular}{llllllll}
\hline Parameter & Almotriptan & Eletriptan & Frovatriptan & Naratriptan & Rizatriptan & Sumatriptan & Zolmitriptan \\
\hline Oral bioavailability (\%) & 69 & 50 & $24-30$ & $63-74$ & 40 & 14 & 40 \\
$T_{1 / 2}$ (hours) & 3.5 & 5 & 25 & $5-6.3$ & 2 & 2 & 3 \\
$T_{\max }$ (hours) & $2-3$ & $1.5-3$ & 3 & $2-3$ & 1 & $2-2.5$ & $2-4$ \\
\hline
\end{tabular}

sumatriptan during lactation. It should be noted that this recommendation is contrary to the SPC, which cautions that "Infant exposure can be minimised by avoiding breastfeeding for 12 hours after treatment, during which time any breast milk expressed should be discarded".

The SPC for eletriptan states that in one study of eight women given a single $80 \mathrm{mg}$ oral dose, the mean total amount of eletriptan in breast milk over 24 hours in this group was $0.02 \%$ of the dose. However, the SPC continues that "caution should be exercised when considering the administration of [eletriptan] to women who are breastfeeding. Infant exposure can be minimised by avoiding breastfeeding for 24 hours after treatment".

Data on exposure during lactation are limited but the SPCs for almotriptan, frovatriptan and rizatriptan recommend avoiding breastfeeding for 24 hours after treatment. The naratriptan and zolmitriptan SPCs state only that "caution should be exercised when considering administration of naratriptan to nursing women".

\section{Drug prophylaxis (Table 4)}

\section{Beta-blockers}

Beta-blockers are not significantly excreted into breast milk and they can be used during breastfeeding. However, attention should be paid to the infant in case of bradycardia and hypoglycaemia. Propranolol or metoprolol are preferred to atenolol.

\section{Antidepressants}

Amitriptyline is detectable in breast milk but low doses used for migraine are unlikely to affect the infant adversely.

\section{Anti-epileptics}

The concentration of sodium valproate found in breast milk is very low so it can be used during breastfeeding. There are insufficient data to recommend gabapentin or topiramate.

\section{Calcium channel blockers}

There is no evidence of any risk associated with the use of verapamil during breastfeeding.

\section{Other drugs}

Safety of pizotifen during breastfeeding is not established, although concentrations in breast milk are not likely to adversely affect the infant. Methysergide is contraindicated.

Although supplemental doses of vitamin B2, vitamin B6 and co-enzyme $Q 10$ are unlikely to affect the infant, high doses recommended for migraine prophylaxis should be avoided (Table 5).

\section{Practical management recommendations}

Analgesics and anti-emetics commonly used for the treatment of migraine can be continued throughout pregnancy. NSAIDs, particularly ibuprofen, can be taken in the first and second trimesters but should be avoided near term. Although a positive recommendation to use triptans during pregnancy cannot be made on the limited data available, women who have taken triptans can be reassured that their use is highly unlikely to result in any adverse outcome. Ergots are contraindicated. If there are no other risk factors involved, inadvertent exposure to any of the drugs used for the treatment of migraine, even those contraindicated for use during pregnancy, does not constitute medical grounds for termination of pregnancy.

When considering the need for prophylaxis during pregnancy, the natural history of improvement during the second and third trimesters should be borne in mind. Consequently, reassurance, identification and avoidance of relevant triggers, adequate hydration and regular meals, together with effective management of acute attacks, is often sufficient. The recommended prophylactic is propranolol. This drug has been widely used and there is no indication of an increased risk of malformations when it is used for migraine prevention during pregnancy. Ideally, the lowest effective dose should be used starting with 10-20 mg twice daily. Propranolol should be stopped 2-3 days before delivery in order to reduce the occurrence of slowed heart rate in the baby and a reduction in uterine contractions. The baby should be monitored for hypoglycaemia. Amitriptyline $10-50 \mathrm{mg}$ at night can be used during the first and second trimester of pregnancy. A further alternative is topiramate. Otherwise healthy pregnant women can use small amounts of ginger to prevent nausea but should avoid high doses.

For symptomatic treatment of migraine when breastfeeding, an appropriate strategy is voltarol 50-100 mg by mouth or via the rectum, up to $200 \mathrm{mg}$ per 24 hours, combined with domperidone $20 \mathrm{mg}$ by mouth or 30-60 mg rectally up to four doses per 24 hours. Domperidone can promote the efficacy of analgesics by reversing gastric stasis in addition to treating nausea.

Sumatriptan can be used during breastfeeding. There is little reason why other triptans with low bioavailability and low absorption by the infant such as zolmitriptan, rizatriptan and eletriptan should not also be used. Even minor exposure could be largely avoided by expressing and discarding all milk for around 4 hours after dosing. Longer periods are not recommended as milk supply can reduce within 48 hours without full and repeated emptying of the breast.

For prophylaxis, propranolol in doses of $10-20 \mathrm{mg}$ twice daily is a first-line strategy.

When recommending use of a drug in contradiction to the prescribing information in the SPC, the risks and benefits should be discussed with the woman, who may choose to use the drug on a named patient basis. The discussion should be documented in the notes.

\section{What to do when nothing works}

In the first instance the diagnosis should be reviewed, as this is the most likely reason for ineffective management. Medication overuse headache can also present during pregnancy and should be considered in any woman regularly taking symptomatic treatments for headache on more than 3 days a week, every week. This usually responds to immediate cessation of symptomatic treatment but may require supportive treatment. ${ }^{39}$ One option to consider in pregnancy is a 6-day reducing course of prednisolone: 60 $\mathrm{mg} /$ day for 2 days, $40 \mathrm{mg} /$ day for 2 days and $20 \mathrm{mg} /$ day for 2 days. 59

During pregnancy and breastfeeding, prochlorperazine $10 \mathrm{mg}$ or chlorpromazine $25-50 \mathrm{mg}$ by intramuscular injection are effective even without additional analgesia, 
and together with intravenous fluids, are usually sufficient to abort an attack. Intravenous magnesium sulphate was well tolerated and effective in a randomised, single-blind, placebo-controlled trial of 30 patients. ${ }^{60} \mathrm{~A}$ combination of intravenous prochlorperazine $10 \mathrm{mg} 8$-hourly together with intravenous magnesium sulphate $1 \mathrm{~g}$ 12-hourly was used successfully to abort two cases of prolonged migraine aura during pregnancy. ${ }^{61}$

\section{Conclusions}

Around $60-70 \%$ of women with migraine will improve in pregnancy, particularly during the second and third trimesters. Most medication is taken during the first trimester, which is the time of most concern for effects on organogenesis. Although therapeutic doses of most migraine treatments do not increase the risk of fetal malformation or miscarriage above the normal background rate, it is sensible to recommend the safest options. For acute treatment, paracetamol is safe throughout pregnancy. Aspirin and NSAIDs are also safe but are best avoided after 30 weeks. NSAIDs (but not aspirin) can be taken during lactation. Prochlorperazine and domperidone are preferred to metoclopramide but all can be used through pregnancy and lactation. Whilst prescription of triptans during pregnancy is not recommended, women inadvertently exposed to triptans during pregnancy can be reassured that there is evidence to support minimal, if any, risk. Sumatriptan can be taken during lactation. For continuing frequent attacks, which warrant prophylaxis, propranolol has best evidence of safety during pregnancy and lactation.

Statements on funding and competing interests

Funding None identified.

Competing interests None identified.

\section{FURTHER INFORMATION}

The National Teratology Information Service (NTIS) Regional Drug and Therapeutics Centre, Wolfson Unit, Claremont Place, Newcastle-upon-Tyne NE2 4HH, UK. Monday-Friday (office hours).

Tel: +44 (0) 191232 1525. Fax: +44 (0) 1912606193

Monday-Friday (1700-2000 for urgent enquiries).

Tel: +44 (0) 1912825944.

NTIS is funded by the Department of Health to provide a national service on all aspects of toxicity of drugs and chemicals in pregnancy throughout the UK.

\section{Sumatriptan and Naratriptan Pregnancy Registry} http://pregnancyregistry.gsk.com

Health care providers can obtain interim registry results and register patients by telephoning the Registry project office directly at +18003362176 (toll-free in the USA) or +19102560549 or by completing the appropriate enrolment form by clicking on the registry name shown below and either returning the form to the registry by fax at +18008001052 or +19102560637 or by mail to: Sumatriptan and Naratriptan Pregnancy Registry, Registries and Epidemiology, Kendle International Inc., Research Park, 1011 Ashes Drive, Wilmington, NC 28405, USA.

Merck Pregnancy Registry Program (Rizatriptan) http://www.merckpregnancyregistries.com/maxalt.html Merck \& Company, Inc., Merck National Service Center. Phone: +18009868999 (toll-free in the USA). Fax: +1 4843442328 .

\section{For information on drugs in pregnancy and} breastfeeding

American Academy of Pediatrics:

http://www.pediatrics.org/cgi/content/full/108/3/776

\section{References}

1 Rasmussen BK, Jensen R, Schroll M, Olesen J. Epidemiology of headache in a general population - a prevalence study. J Clin Epidemiol 1991: 44: 1147-1157.

2 Higgins J, Green S (eds). Cochrane Handbook for Systematic Reviews of Interventions 4.2.6 (updated September 2006). Chichester, UK: John Wiley \& Sons, 2006.

3 Bonati M, Bortolus R, Marchetti F, Romero M, Tognoni G. Drug use in pregnancy: an overview of epidemiological (drug utilization) studies. Eur J Clin Pharmacol 1990; 38: 325-328.

4 Ashkenazi J, Goldman JA, Dicker D, Feldberg D, Goldman GA. Adverse neurological symptoms after gonadotropin-releasing hormone analog therapy for in vitro fertilization cycles. Fertil Steril 1990; 53: 738-740.

5 Amir BY, Yaacov B, Guy B, Gad P, Itzhak W, Gal I. Headaches in women undergoing in vitro fertilization and embryo-transfer treatment. Headache 2005; 45: 215-219.

6 Aromaa M, Rautava P, Helenius H, Sillanpää ML. Prepregnancy headache and the well-being of mother and newborn. Headache 1996; 36: 409-415.

7 Marcus DA, Scharff L, Turk D. Longitudinal prospective study of headache during pregnancy and postpartum. Headache 1999; 39: 625-632.

8 Sances G, Granella F, Nappi RE, Fignon A, Ghiotto N, Polatti F, et al. Course of migraine during pregnancy and postpartum: a prospective study. Cephalalgia 2003; 23: 197-205.

9 Granella F, Sances G, Pucci E, Nappi RE, Ghiotto N, Napp G. Migraine with aura and reproductive life events: a case control study. Cephalalgia 2000; 20: 701-707.

10 Melhado E, Maciel JA Jr, Guerreiro CA. Headaches during pregnancy in women with a prior history of menstrual headaches. Arq Neuropsiquiatr 2005; 63: 934-940.

11 Wright G, Patel M. Focal migraine and pregnancy. BMJ 1986; 293: $1557-1558$

12 Chancellor AM, Wroe SJ, Cull RE. Migraine occurring for the first time in pregnancy. Headache 1990; 30: 224-227.

13 Cupini LM, Matteis M, Troisi E, Calabresi P, Bernardi G, Silvestrini $M$. Sex-hormone-related events in migrainous females. A clinical comparative study between migraine with aura and migraine without aura. Cephalalgia 1995; 15: 140-144.

14 Mandel S. Hemiplegic migraine in pregnancy. Headache 1988; 28: $414-416$.

15 Wainscott G, Sullivan M, Volans G, Wilkinson M. The outcome of pregnancy in women suffering from migraine. Postgrad Med 1978; 54: 98-102.

16 Maggioni F, Alessi C, Maggino T, Zanchin G. Headache during pregnancy. Cephalalgia 1997; 17: 765-769.

17 Banhidy F, Acs N, Horvath-Puho E, Czeizel AE. Maternal severe migraine and risk of congenital limb deficiencies. Birth Defects Res A Clin Mol Teratol 2006; 76: 592-601.

18 Rotton WN, Sachtleben MR, Friedman EA. Migraine and eclampsia. Obstet Gynecol 1959; 14: 332-330.

19 Moore MP, Redman CW. Case-control study of severe preeclampsia of early onset. BMJ 1983; 287: 580-583.

20 Marcoux S, Berube S, Brisson J, Fabia J. History of migraine and risk of pregnancy-induced hypertension. Epidemiology 1992; 3: 53-56.

21 Facchinetti F, Allais G, D'Amico R, Benedetto C, Volpe A. The relationship between headache and preeclampsia: a casecontrol study. Eur J Obstet Gynecol Reprod Biol 2005; 121 : 143-148.

22 Scher Al, Terwindt GM, Picavet HS, Verschuren WM, Ferrari MD, Launer LJ. Cardiovascular risk factors and migraine: the GEM population-based study. Neurology 2005; 64: 614-620.

23 Banhidy F, Acs N, Horvath-Puho E, Czeizel AE. Pregnancy complications and delivery outcomes in pregnant women with severe migraine. Eur J Obstet Gynecol Reprod Biol 2006 [Epub 8 November 2006].

24 Adeney KL, Williams MA, Miller RS, Frederick IO, Sorensen TK, Luthy DA. Risk of preeclampsia in relation to maternal history of migraine headaches. J Matern Fetal Neonatal Med 2005; 18: 167-172.

25 Stein G, Morton J, Marsh A, Collins W, Branch C, Desaga U, et al. Headaches after childbirth. Acta Neurol Scand 1984; 69: 74-79.

26 Scharff L, Marcus DA, Turk DC. Headache during pregnancy and in the postpartum: a prospective study. Headache 1997; 37: 203-210.

27 Kittner SJ, Stern BJ, Feeser BR, Hebel R, Nagey DA, Buchholz DW, et al. Pregnancy and the risk of stroke. N Engl J Med 1996; 335: 768-774.

28 James $A H$, Bushnell CD, Jamison MG, Myers ER. Incidence and risk factors for stroke in pregnancy and the puerperium. Obstet Gynecol 2005; 106: 509-516. 
29 MacGregor EA, Frith A, Ellis J, Aspinall L, Hackshaw A. Incidence of migraine relative to menstrual cycle phases of rising and falling estrogen. Neurology 2006; 67: 2154-2158.

30 MacGregor EA, Frith A, Ellis J, Aspinall L, Hackshaw A. Prevention of menstrual attacks of migraine: a double-blind placebo-controlled crossover study. Neurology 2006; 67: 2159-2163.

31 Campbell OM, Gray RH. Characteristics and determinants of postpartum ovarian function in women in the United States. Am J Obstet Gynecol 1993; 169: 55-60.

32 Dawson-Basoa MB, Gintzler AR. 17-Beta-estradiol and progesterone modulate an intrinsic opioid analgesic system. Brain Res 1993; 601: 241-245.

33 Hanington E. Migraine is a platelet disorder. Headache 1987; 27: 401-402.

34 Bonnar AJ, NcNicol GP, Douglas AS. Coagulation and fibrinolytic mechanisms during and after normal childbirth. BMJ 1970; 2: 200-203.

35 Redman CW, Bonnar J, Beilin LJ. Early platelet consumption in pre-eclampsia. BMJ 1978; 1: 467-469.

36 Amery WK, Vandenbergh V. What can precipitating factors teach us about the pathogenesis of migraine? Headache 1987; 27: $146-150$.

37 The National Teratology Information Service. http://www. spib.axl.co.uk [Accessed 25 December 2006]

38 Slone D, Siskind V, Heinonen OP, Monson RR, Kaufman DW, Shapiro S. Aspirin and congenital malformation. Lancet 1976; 1: 1373-1375.

39 Steiner TJ, MacGregor EA, Davies PTG. Guidelines for All Doctors in the Diagnosis and Management of Migraine and Tension-Type Headache (2nd edn) (British Association for the Study of Headache Management Guidelines). 2004. http://64.227.208.149/NS_BASH/BASH_guidelines_1Feb06. pdf [Accessed 25 December 2006]

40 Byron M. Treatment of rheumatic diseases. In: Rubin P (ed.), Prescribing in Pregnancy (3rd edn). London, UK: BMJ Books, 2000; 87-100.

41 Czeizel AE. Teratogenicity of ergotamine. J Med Genet 1989; 26: 69-70.

42 Reiff-Eldridge R, Heffner CR, Ephross SA, Tennis PS, White AD, Andrews EB. Monitoring pregnancy outcomes after prenatal drug exposure through prospective pregnancy registries: a pharmaceutical company commitment. $A m ~ J$ Obstet Gynecol 2000; 182: 159-163.

43 Shuhaiber S, Pastuszak A, Schick B, Matsui D, Spivey G, Brochu J, et al. Pregnancy outcome following first trimester exposure to sumatriptan. Neurology 1998; 51: 581-583.

44 O'Quinn S, Ephross SA, Williams V, Davis RL, Gutterman DL, Fox AW. Pregnancy and perinatal outcomes in migraineurs using sumatriptan: a prospective study. Arch Gynecol Obstet 1999; 263: 7-12.

45 Olesen C, Steffensen FH, Sorensen HT, Nielsen GL, Olsen J. Pregnancy outcome following prescription for sumatriptan. Headache 2000; 40: 20-24.

46 Kallen B, Lygner P. Delivery outcome in women who used drugs for migraine during pregnancy with special reference to sumatriptan. Headache 2001; 41: 351-356.

47 Marcus DA, Scharff L, Turk DC. Nonpharmacological management of headaches during pregnancy. Psychosom Med 1995; 57: 527-535.

48 Scharff L, Marcus DA, Turk DC. Maintenance of effects in the nonmedical treatment of headaches during pregnancy. Headache 1996; 36: 285-290.

49 Nelson-Piercy C, De Swiet M. Diagnosis and management of migraine. Low dose aspirin may be used for prophylaxis. BMJ
1996; 313: 691-692.

50 Butters L, Kennedy S, Rubin P. Atenolol in essential hypertension during pregnancy. BMJ 1990; 301: 587-589.

51 Habib A, McCarthy JS. Effects on the neonate of propranolol administered during pregnancy. J Pediatr 1977; 91: 808-811.

52 Lindhout D, Schmidt D. In utero exposure to valproate and neural tube defects. Lancet 1986; 1: 1392-1393.

53 Buckner KD, Chavez ML, Raney EC, Stoehr JD. Health food stores' recommendations for nausea and migraines during pregnancy. Ann Pharmacother 2005; 39: 274-279.

54 Marcus DM, Snodgrass WR. Do no harm: avoidance of herbal medicines during pregnancy. Obstet Gynecol 2005; 105(5 Pt 1): $1119-1122$

55 Borrelli F, Capasso R, Aviello G, Pittler MH, Izzo AA. Effectiveness and safety of ginger in the treatment of pregnancy-induced nausea and vomiting. Obstet Gynecol 2005; 105: 849-856.

56 Emelianova S, Mazzotto P, Einarson A, Koren G. Prevalence and severity of nausea and vomiting of pregnancy and effect of vitamin supplementation. Clin Invest Med 1999; 22: 106-110.

57 Ahluwalia IB, Morrow B, Hsia J. Why do women stop breastfeeding? Findings from the Pregnancy Risk Assessment and Monitoring System. Pediatrics 2005; 116: 1408-1412.

58 Wojnar-Horton RE, Hackett LP, Yapp P, Dusci LJ, Paech M, llett KF. Distribution and excretion of sumatriptan in human milk. $\mathrm{Br}$ J Clin Pharmacol 1996; 41: 217-221.

59 Krymchantowski AV, Barbosa JS. Prednisone as initial treatment of analgesic-induced daily headache. Cephalalgia 2000; 20: 107-113.

60 Demirkaya S, Vural O, Dora B, Topcuoglu MA. Efficacy of intravenous magnesium sulfate in the treatment of acute migraine attacks. Headache 2001; 41: 171-177.

61 Rozen TD. Aborting a prolonged migrainous aura with intravenous prochlorperazine and magnesium sulfate. Headache 2003; 43: 901-903.

62 Lance J, Anthony M. Some clinical aspects of migraine. Arch Neurol 1966; 15: 356-361.

63 Somerville BW. A study of migraine in pregnancy. Neurology 1972; 22: 824-828.

64 Manzoni GC, Farina S, Granella F, Alfieri M, Bisi M. Classic and common migraine suggestive clinical evidence of two separate entities. Funct Neurol 1986; 1: 112-122.

65 Ratinahirana $H$, Darbois $Y$, Bousser M-G. Migraine and pregnancy: a prospective study in 703 women after delivery. Neurology 1990; 40(Suppl. 1): 437.

66 Rasmussen BK, Olesen J. Migraine with aura and migraine without aura: an epidemiological study. Cephalalgia 1992; 12: 221-228.

67 Granella F, Sances G, Zanferrari C, Costa A, Martignoni E, Manzoni GC. Migraine without aura and reproductive life events: a clinical epidemiological study in 1300 women. Headache 1993; 33: 385-389.

68 Chen T-C, Leviton A. Headache recurrence in pregnant women with migraine. Headache 1994; 34: 107-110.

69 MacGregor EA, Igarashi $H$, Wilkinson M. Headaches and hormones: subjective versus objective assessment. Headache Quarterly 1997; 8: 126-136.

70 Kelman L. Women's issues of migraine in tertiary care. Headache 2004; 44: 2-7.

71 Ertresvag JM, Zwart JA, Helde G, Johnsen HJ, Bovim G. Headache and transient focal neurological symptoms during pregnancy, a prospective cohort. Acta Neurol Scand 2005; 111: 233-237.

72 http://www.perinatology.com/exposures/druglist.htm [Accessed 30 December 2006].

\section{READERS' CONTRIBUTIONS INVITED ON 'A BETTER WAY OF WORKING'}

Continuing in this issue (see article on page 78) is the feature entitled 'A Better Way of Working', the purpose of which is to disseminate service delivery suggestions likely to be of interest and relevance to the Journal's readership.

Readers are invited to submit suggestions based on their own personal experience for consideration by the Journal Editor Contributions should not exceed 250-500 words and should be written in a standardised format responding to the following four questions (or similar): Why was change needed? How did you go about implementing change? What advice would you give to others who might be considering a similar course of action? How did you show that the change had occurred?

All contributions should be submitted via the Journal's online submission system at http://jfprhc.allentrack.net. 